\title{
CO oxidation on Pd(111), Pt(111), and Rh(111) surfaces studied by infrared chemiluminescence spectroscopy
}

Kenji Nakao, Osamu Watanabe, Toshiaki Sasaki,

Shin-ichi Ito, Keiichi Tomishige, Kimio Kunimori*

Institute of Materials Science, University of Tsukuba

1-1-1 Tennodai, Tsukuba, Ibaraki 305-8573, Japan

Tel: +81-29-853-5026, Fax: +81-29-853-4490

E-mail: kunimori@ims.tsukuba.ac.jp (K. Kunimori)

* To whom correspondence should be addressed. 


\section{Abstract}

The infrared (IR) chemiluminescence studies of $\mathrm{CO}_{2}$ formed during steady-state $\mathrm{CO}$ oxidation over $\operatorname{Pd}(111), \operatorname{Pt}(111)$, and $\operatorname{Rh}(111)$ surfaces were carried out. Analysis of their emission spectra indicates that the order of the average vibrational temperature $\left(T_{\mathrm{V}}{ }^{\mathrm{AV}}\right)$ values of $\mathrm{CO}_{2}$ formed during CO oxidation was as follows: $\operatorname{Pd}(111)>\operatorname{Pt}(111)>\operatorname{Rh}(111)$, and the order is coincident with the potential energy in the transition state expected by the theoretical calculations. Furthermore, it is suggested that the bending vibrational temperature $\left(T_{\mathrm{V}}{ }^{\mathrm{B}}\right)$ can also be influenced by the angle of $\mathrm{O}-\mathrm{C}-\mathrm{O}\left(\angle_{\mathrm{OCO}}\right)$ of the activated complex in the transition state, which has also been proposed by the theoretical calculations.

Keywords: IR chemiluminescence; Carbon dioxide; Carbon monoxide; CO oxidation; Noble metal 


\section{Introduction}

The catalytic oxidation of carbon monoxide (CO) on platinum group metal surfaces has been one of the most widely studied surface-catalyzed reactions [1-17]. The reaction is of practical importance for the environmental pollution control. On the other hand, the reaction is also of scientific interest because the total reaction can be divided into a few elementary steps and the theoretical approaches can be applied to the reaction to describe the kinetics of the surface-catalyzed reaction. In contrast, in order to elucidate the dynamics of the surface-catalyzed reaction, it is effective to investigate internal (vibrational and rotational) [6-14] and translational [15] energy of product molecules. Measurements of the vibrational and rotational states of the product $\mathrm{CO}_{2}$ molecules have been performed by infrared chemiluminescence (IR emission) technique [6-14]. Analysis of the vibrational states can give the information on the structure of the activated $\mathrm{CO}_{2}$ complex (i.e., the dynamics of $\mathrm{CO}$ oxidation) from which the gas-phase molecules desorbed.

Coulston and Haller [6] studied the dynamics of $\mathrm{CO}$ oxidation on polycrystalline $\mathrm{Pd}, \mathrm{Pt}$, and Rh surfaces by measuring high-resolution IR emission spectra and reported that the order of the apparent vibrational temperatures are as follows: $\mathrm{Pd}>\mathrm{Pt}>\mathrm{Rh}$. Our group has reported IR emission of $\mathrm{CO}_{2}$ from steady-state $\mathrm{CO}$ oxidation on single-crystal $\mathrm{Pd}$ and $\mathrm{Pt}$ surfaces combined with kinetic results [9-14]. These suggest that the activated complex of $\mathrm{CO}_{2}$ formation (i.e., the transition state of $\mathrm{CO}_{2}$ formation from $\mathrm{CO}(\mathrm{a})+\mathrm{O}(\mathrm{a})$ ) had more bent structure on $\mathrm{Pd}(111)$ and less bent structure on $\operatorname{Pt}(111)$, since the bending mode of $\mathrm{CO}_{2}$ from $\mathrm{Pd}(111)$ was more vibrationally excited than that of $\mathrm{CO}_{2}$ from $\mathrm{Pt}(111)$ [12,13]. Furthermore, we have confirmed that the product $\mathrm{CO}_{2}$ molecules on $\operatorname{Pd}(111)$ and $\operatorname{Pd}(110)$ was also rotationally excited [12]. These results indicate that the IR 
chemiluminescence method can provide a direct energetic evidence of the reaction mechanism and the activated complex of $\mathrm{CO}_{2}$ formation.

In this article, the dynamics of $\mathrm{CO}_{2}$ formation during the $\mathrm{CO}$ oxidation over single-crystal $\mathrm{Rh}(111)$ surface is reported, and this corresponds to the first presentation of the IR emission studies on a single-crystal $\mathrm{Rh}$ surface. The obtained results were compared with those on $\operatorname{Pd}(111)$ and $\operatorname{Pt}(111)$, and the tendency was interpreted from the comparison between the experimental results and the reported theoretical studies on the transition state of CO oxidation.

\section{Experimental}

A molecular-beam reaction system, in combination with a FT-IR spectrometer (InSb detector Nexus670; Thermo Electron Corp.) was used to measure IR emissions of product $\mathrm{CO}_{2}$ molecules just desorbed from metal surfaces during catalytic reactions [10-14]. A UHV chamber (base pressure $<1.0 \times 10^{-9}$ Torr) was equipped with a $\mathrm{CaF}_{2}$ lens, which collected $\mathrm{IR}$ emission, an $\mathrm{Ar}^{+}$ion gun for sample cleaning, and a quadrupole mass spectrometer (QMS, QME200; Pfeiffer Vacuum Technology AG) with a differential pumping system. Two free-jet molecular-beam nozzles $(0.1 \mathrm{~mm}$ diameter orifice) supplied the reactant gases. The reactant fluxes were controlled using mass flow controllers. The $\mathrm{CO}$ and $\mathrm{O}_{2}$ gases (total flux of $8.2 \times 10^{18} \mathrm{~cm}^{-2} \mathrm{~s}^{-1} ; \mathrm{CO} / \mathrm{O}_{2}=1$ ) were exposed to single-crystal surfaces $(\mathrm{Pd}(111), \mathrm{Pt}(111)$, and $\mathrm{Rh}(111))$. Steady-state $\mathrm{CO}$ oxidation was performed at temperatures of 400-900 K. Another UHV chamber (base pressure $<2.0 \times 10^{-10}$ Torr) was used to prepare and characterize the clean surfaces. It was equipped with a molecular-beam reaction system, an $\mathrm{Ar}^{+}$ion gun, low energy electron diffraction (LEED), and a QMS. Before the molecular-beam 
reaction, the single-crystal surfaces were cleaned using a standard procedure $\left(\mathrm{O}_{2}\right.$ treatment, $\mathrm{Ar}^{+}$ bombardment and annealing) [9-14]. After cleaning, the sharp $(1 \times 1)$ LEED pattern was observed.

The IR emission spectra of the $\mathrm{CO}_{2}$ molecules desorbed from the surface were measured with $4 \mathrm{~cm}^{-1}$ resolution. At that low resolution, no individual vibration-rotation lines were resolved. The IR emission spectra were analyzed based on simulation of model spectra $[7,12,13]$. The average vibrational Boltzmann temperature $\left(T_{\mathrm{V}}{ }^{\mathrm{AV}}\right.$ : an average temperature of the antisymmetric stretching, symmetric stretching and bending modes), which was calculated from the degree of the red-shift from the fundamental band $\left(2349 \mathrm{~cm}^{-1}\right)$ [7,9-13]. The emission intensity is related to the extent of excitation in the antisymmetric stretching of $\mathrm{CO}_{2}$ [11-14]. Therefore, the antisymmetric vibrational temperature $\left(T_{\mathrm{V}}{ }^{\mathrm{AS}}\right)$ can be estimated from the normalized emission intensity [11-14]. Based on $T_{\mathrm{V}}{ }^{A V}$ and $T_{\mathrm{V}}{ }^{\mathrm{AS}}$, it is possible to deduce the bending vibrational temperature $\left(T_{\mathrm{V}}{ }^{\mathrm{B}}\right)$. The relation between $T_{\mathrm{V}}{ }^{\mathrm{AV}}$ and respective vibrational temperature is represented as

$$
T_{\mathrm{V}}^{\mathrm{AV}}=\left(T_{\mathrm{V}}^{\mathrm{AS}}+T_{\mathrm{V}}^{\mathrm{SS}}+2 T_{\mathrm{V}}^{\mathrm{B}}\right) / 4
$$

where $2 T_{\mathrm{V}}{ }^{\mathrm{B}}$ corresponds to the degeneration of the bending vibration. Assuming that $T_{\mathrm{V}}{ }^{\mathrm{B}}$ is equal to $T_{\mathrm{V}}{ }^{\mathrm{SS}}$ because of the Fermi resonance [6,8], $T_{\mathrm{V}}^{\mathrm{B}}$ is expected to be $\left(4 T_{\mathrm{V}}{ }^{\mathrm{AV}}-T_{\mathrm{V}}{ }^{\mathrm{AS}}\right) / 3$. This assumption is plausible on the basis of previous reports [6,8]. It should be added that $T_{\mathrm{V}}{ }^{\mathrm{AV}}, T_{\mathrm{V}}{ }^{\mathrm{AS}}$ and $T_{\mathrm{V}}{ }^{\mathrm{B}}$ were used here as parameters to characterize the extent of the vibrational excitation of the product $\mathrm{CO}_{2}$. It took about 30-90 min for the measurement of the IR emission spectra with 2000-6000 scans. The stable steady-state activity was obtained during the measurement. 


\section{Results and Discussion}

Figure 1(a) shows the rate of $\mathrm{CO}_{2}$ formation in the steady-state $\mathrm{CO}$ oxidation on $\mathrm{Pd}(111)$, $\operatorname{Pt}(111)$, and $\mathrm{Rh}(111)$ as a function of surface temperature $\left(T_{\mathrm{S}}\right)\left(\mathrm{CO} / \mathrm{O}_{2}=1\right)$. The $\mathrm{CO}$ oxidation proceeded above $500 \mathrm{~K}$ on $\mathrm{Pd}(111)$ and $\mathrm{Rh}(111)$, and $550 \mathrm{~K}$ on $\mathrm{Pt}(111)$. The surface temperature dependence of the formation rate showed a maximum on all the surfaces. The behavior agrees well with the general Langmuir-Hinshelwood ( $\mathrm{LH})$ kinetics of $\mathrm{CO}$ oxidation on noble metal (Pd $[1,4,6,12]$, Pt $[2,6,13]$, and $\mathrm{Rh}[3,5,6])$ surfaces. The temperature at which the highest activity was obtained is denoted as $T_{\mathrm{S}}{ }^{\max }$. At temperatures lower than $T_{\mathrm{S}}{ }^{\max }$, the surface coverage of CO is known to be high. The rate-determining step is $\mathrm{O}_{2}$ adsorption on the vacant site, which is formed by the desorption of $\mathrm{CO}(\mathrm{a})$. At temperatures higher than $T_{\mathrm{S}}{ }^{\mathrm{max}}$, the formation rate of $\mathrm{CO}_{2}$ decreased gradually with increasing surface temperature. This behavior is attributable to the decreased $\mathrm{CO}$ coverage. The starting temperatures of reaction and $T_{\mathrm{S}}{ }^{\max }$ on $\mathrm{Pd}(111), \operatorname{Pt}(111)$ and $\mathrm{Rh}(111)$, i.e., 650, 775 and $650 \mathrm{~K}$, respectively, are similar to those on polycrystalline surfaces reported by Coulston and Haller [6]. In contrast, the order of production rate of our results $(\operatorname{Pd}(111)>\operatorname{Rh}(111)>\operatorname{Pt}(111))$ at $T_{\mathrm{S}}{ }^{\max }$ is different from results of polycrystalline surfaces $(\mathrm{Pd}>\mathrm{Pt}>\mathrm{Rh}$ [6]). Generally, a polycrystalline surface consists of low-index planes such as (111), (100) and (110) [17]. It has been reported that the maximum production rate was strongly dependent on surface structure. In the case of $\operatorname{Pd}$ and $\mathrm{Rh}$, the order is $\operatorname{Pd}(100)>\operatorname{Pd}(110)>\operatorname{Pd}(111)$ [9], and $\operatorname{Rh}(100) \approx \operatorname{Rh}(111)$ [3]. Therefore, it is thought that polycrystalline $\mathrm{Pd}$ surface can give higher catalytic activity than $\operatorname{Pd}(111)$, and polycrystalline $\mathrm{Rh}$ surface can be comparable to $\mathrm{Rh}(111)$. Unfortunately, there is no report on the comparison in catalytic activity on Pt low-index surfaces, however, the different order between the polycrystalline and single-crystal surfaces presented here suggests $\operatorname{Pt}(100)>\operatorname{Pt}(111)$ and $\operatorname{Pt}(110)>$ 
$\operatorname{Pt}(111)$. The $\mathrm{CO}_{2}$ formation rate is plotted as a function of inverse surface temperature in the Arrhenius form as shown Figure 1(b). From the low temperature range $T_{\mathrm{S}}=475-600 \mathrm{~K}$ of this plot, the apparent activation energy $\left(E_{\text {app }}\right)$ of $\mathrm{Pd}(111)$ is estimated as $27.8 \mathrm{kcal} / \mathrm{mol}$, from $T_{\mathrm{S}}=550-625 \mathrm{~K}$, that of $\mathrm{Pt}(111)$ is estimated as $19.0 \mathrm{kcal} / \mathrm{mol}$, and from $T_{\mathrm{S}}=550-575 \mathrm{~K}$, that of $\mathrm{Rh}(111)$ is estimated as $22.2 \mathrm{kcal} / \mathrm{mol}$. These values agree with the value of $28.1 \mathrm{kcal} / \mathrm{mol}$ on $\mathrm{Pd}(111)$ [4], which was obtained by Goodman et al., that of $24.1 \mathrm{kcal} / \mathrm{mol}$ on $\mathrm{Pt}(111)$ [2], which was obtained by Ertl et al., and that of $19.9 \mathrm{kcal} / \mathrm{mol}$ on $\mathrm{Rh}(111)$ [5], which was obtained by Schmidt et al.. It has been reported that the surface is oxidized during the $\mathrm{CO}$ oxidation in high reaction pressure (about 10 Torr) or low $\mathrm{CO} / \mathrm{O}_{2}$ ratio conditions $\left(\mathrm{CO} / \mathrm{O}_{2}=1 / 30\right)$, especially in the case of $\mathrm{Rh}$ surface [3]. However, we think that the surface keeps metallic state, because our reaction pressure $\left(\sim 10^{-2}\right.$ Torr $)$ is three orders of magnitude lower than their condition, and the pressure ratio is $\mathrm{CO} / \mathrm{O}_{2}=1 / 1$.

Figure 2 shows IR emission spectra of $\mathrm{CO}_{2}$ molecules produced by the $\mathrm{CO}$ oxidation on $\mathrm{Rh}(111)$ surface at various surface temperatures. The $\mathrm{CO}_{2}$ emission spectra were observed in the region of $2400-2220 \mathrm{~cm}^{-1}$, while the emission spectra centered at $2143 \mathrm{~cm}^{-1}$ are due to the IR emission of the non-reacted $\mathrm{CO}$ molecules, which are scattered from the surface. The $\mathrm{CO}_{2}$ emission spectra are considerably red-shifted from $2349 \mathrm{~cm}^{-1}$ (the fundamental band of antisymmetric stretch). The degree of the red-shift from the fundamental band, which reflects the average vibrational state of the excited $\mathrm{CO}_{2}$ molecules, is not strongly influenced by the surface temperatures. The emission intensity is also almost constant under various surface temperatures.

Figure 3 shows the average vibrational temperature $\left(T_{\mathrm{V}}{ }^{\mathrm{AV}}\right)$ derived from IR emission spectra of $\mathrm{CO}_{2}$ on $\mathrm{Pd}(111), \operatorname{Pt}(111)$ and $\mathrm{Rh}(111)$ surfaces as a function of surface temperature. The $T_{\mathrm{V}}{ }^{\mathrm{AV}}$ values are much greater than $T_{\mathrm{S}}$, which indicates that the product $\mathrm{CO}_{2}$ is vibrationally excited. It is shown 
that the order of $T_{\mathrm{V}}{ }^{\mathrm{AV}}$ is as follows: $\operatorname{Pd}(111)>\operatorname{Pt}(111)>\operatorname{Rh}(111)$. This tendency agrees well with the results of polycrystalline $\mathrm{Pd}, \mathrm{Pt}$, and Rh surfaces studied by Coulston and Haller [6]. In addition, the $T_{\mathrm{V}}{ }^{\mathrm{AV}}$ values on $\operatorname{Pd}(111)$ is much more dependent on the $T_{\mathrm{S}}$ than those on $\operatorname{Pt}(111)$ and $\operatorname{Rh}(111)$. The reason for different surface temperature dependence on these surfaces is not clear at present.

Eichler [16] has studied CO oxidation on transition metal surfaces using density functional theory (DFT) calculations. He reported that the potential energies of transition state $\left(E_{\mathrm{TS}}\right)$ and the activation energies $\left(E_{\mathrm{a}}\right)$ in $\mathrm{CO}$ oxidation on $\operatorname{Pd}(111), \operatorname{Pt}(111)$ and $\operatorname{Rh}(111)$ as listed in Table 1, and the potential energy diagram is illustrated in Figure 4 . He exhibited that the $E_{\mathrm{TS}}$ values in $\mathrm{CO}$ oxidation on $\operatorname{Pd}(111), \operatorname{Pt}(111)$ and $\mathrm{Rh}(111)$ were $-0.98,-1.38$ and $-1.88 \mathrm{eV}$, respectively [16], that is, the transition state on $\operatorname{Pd}(111)$ has the highest potential energy and that on $\operatorname{Rh}(111)$ is the lowest one. IR emission measurements are reflected by the excited energy ( $\left.E_{\text {excited }}\right)$ of the product $\mathrm{CO}_{2}$, which can be distributed to internal (vibrational and rotational) and translational energies of desorbed $\mathrm{CO}_{2}$ molecules. Therefore, it is suggested that the excitation level of desorbed $\mathrm{CO}_{2}$ can be originated from the height of potential energy of the transition state as shown in Figure 4.

Figure 5 shows the bending vibrational temperature $\left(T_{\mathrm{V}}{ }^{\mathrm{B}}\right)$ and the antisymmetric vibrational temperature $\left(T_{\mathrm{V}}{ }^{\mathrm{AS}}\right)$ obtained from the IR emission intensity of $\mathrm{CO}_{2}$ as a function of surface temperature. The $T_{\mathrm{V}}{ }^{\mathrm{B}}$ values are higher than those of $T_{\mathrm{V}}{ }^{\mathrm{AS}}$ on each surface, which means that the bending vibrational mode is more excited than the antisymmetric vibrational mode on each surface. However, the bending vibrational temperature at $T_{\mathrm{S}}=800 \mathrm{~K}$ is much higher on $\operatorname{Pd}(111)\left(T_{\mathrm{V}}{ }^{\mathrm{B}}=2200\right.$ K) than on $\operatorname{Pt}(111)\left(T_{\mathrm{V}}{ }^{\mathrm{B}}=1750 \mathrm{~K}\right)$ and $\operatorname{Rh}(111)\left(T_{\mathrm{V}}{ }^{\mathrm{B}}=1400 \mathrm{~K}\right)$ as shown in Fig. 5(a). The higher vibrational temperatures on $\mathrm{Pd}(111)$, compared to $\mathrm{Pt}(111)$ or $\mathrm{Rh}(111)$, are in good agreement with the polycrystalline results of Coulston and Haller [6]. They argued that the excess bending 
excitation in the case of Pd might be due to the higher density of states at Fermi level compared to Pt or Rh. In fact, the antisymmetric vibrational temperature on $\operatorname{Pd}(111)$ was also rather high, and this can be corresponded to higher potential energy of the transition state (Table 1). Regarding $\operatorname{Pt}(111)$ and $\mathrm{Rh}(111)$, the bending vibrational temperature of $\operatorname{Pt}(111)$ was higher than that of $\operatorname{Rh}(111)$ and this can be related to the angle of $\mathrm{O}-\mathrm{C}-\mathrm{O}\left(\angle_{\mathrm{OCO}}\right)$ in the transition state. Eichler [16] has also reported that the $\angle_{\mathrm{OCO}}$ in the transition states on $\operatorname{Pt}(111)$ and $\operatorname{Rh}(111)$ were $109^{\circ}$ and $112^{\circ}$, respectively, as shown in Table 1 . In addition, the smaller the $\angle_{\mathrm{OCO}}$ at the transition state, the larger the energy amount in the bending vibrational mode of desorbed $\mathrm{CO}_{2}$ molecules. This can be explain the difference in the bending vibrational temperature on $\operatorname{Pt}(111)$ and $\mathrm{Rh}(111)$. On the other hand, in the case of $\mathrm{Pd}(111)$, the angle is relatively large like $\mathrm{Rh}(111)$. However, the product $\mathrm{CO}_{2}$ molecules on $\operatorname{Pd}(111)$ are much more excited in both bending and antisymmetric vibrations than those on $\operatorname{Pt}(111)$ and $\mathrm{Rh}(111)$. At present, it is interpreted that the vibrational excited states on $\operatorname{Pd}(111)$ can be controlled mainly by the large excited energy $\left(E_{\text {excited }}\right)$ than by the angle of activated complex in the transition state.

\section{Conclusions}

We measured the steady-state activity of $\mathrm{CO}$ oxidation over $\operatorname{Pd}(111), \operatorname{Pt}(111)$, and $\operatorname{Rh}(111)$ surfaces in the temperature range of 400-900 K. Measurements and analyses of IR chemiluminescence of $\mathrm{CO}_{2}$ formed during the steady-state $\mathrm{CO}$ oxidation supplied the vibrational energy states of $\mathrm{CO}_{2}$, as the average vibrational temperature $\left(T_{\mathrm{V}}{ }^{\mathrm{AV}}\right)$, antisymmetric vibrational temperature $\left(T_{\mathrm{V}}{ }^{\mathrm{AS}}\right)$, and bending vibrational temperature $\left(T_{\mathrm{V}}^{\mathrm{B}}\right)$. The order of the $T_{\mathrm{V}}{ }^{\mathrm{AV}}$ values of $\mathrm{CO}_{2}$ 
formed during $\mathrm{CO}$ oxidation was as follows: $\operatorname{Pd}(111)>\operatorname{Pt}(111)>\operatorname{Rh}(111)$. It is suggested that the order corresponds to the potential energy of the transition state expected from the theoretical studies. The $T_{\mathrm{V}}{ }^{\mathrm{B}}$ values are higher than those of $T_{\mathrm{V}}{ }^{\mathrm{AS}}$ on each surface, which means that the bending vibrational mode is more excited than the antisymmetric vibrational mode. The order of the $T_{\mathrm{V}}{ }^{\mathrm{B}}$ was as follows: $\operatorname{Pd}(111)>\operatorname{Pt}(111)>\operatorname{Rh}(111)$, and this can be influenced by both the angle of the activated complex $(\angle \mathrm{OCO})$ and $E_{\text {excited. }}$

\section{Acknowledgement}

This work was supported by the $21^{\text {st }}$ Century Center of Excellence (COE) Program of the Ministry of Education, Culture, Sports, Science and Technology (MEXT), Japan. K. Nakao is grateful for his Research Fellowship from the Japan Society for Promotion of Science (JSPS) for Young Scientists. 


\section{References}

[1] T. Engel and G. Ertl, Adv. Catal. 28 (1979) 1.

[2] C.T. Campbell, G. Ertl, H. Kuipers and J. Segner, J. Chem. Phys. 73 (1980) 5862.

[3] C.H.F. Peden, D.W. Goodman, D.S. Blair, P.J. Berlowitz, G.B. Fisher and S.H. Oh, J. Phys. Chem. 92 (1988) 1563.

[4] J. Szanyi, W.N. Kuhn and D.W. Goodman, J. Phys. Chem. 98 (1994) 2978.

[5] S.B. Schwartz, L.D. Schmidt and G.B. Fisher, J. Phys. Chem. 90 (1986) 6194.

[6] S.W. Coulston and G.L. Haller, J. Chem. Phys. 95 (1991) 6932.

[7] D.A. Mantell, K. Kunimori, S.B. Ryali, G.L. Haller and J.B. Fenn, Surf. Sci. 172 (1986) 281.

[8] D.J. Bald and S.L. Bernasek, J. Chem. Phys. 109 (1998) 746.

[9] H. Uetsuka, K. Watanabe, H. Ohnuma and K. Kunimori, Surf. Rev. Lett. 4 (1997) 1359.

[10] H. Uetsuka, K. Watanabe, H. Kimpara and K, Kunimori, Langmuir 15 (1999) 5795.

[11] K. Nakao, S. Ito, K. Tomishige and K. Kunimori, Chem. Phys. Lett. 410 (2005) 86.

[12] K. Nakao, S. Ito, K. Tomishige and K. Kunimori, J. Phys. Chem. B 109 (2005) 17553.

[13] K. Nakao, S. Ito, K. Tomishige and K. Kunimori, J. Phys. Chem. B 109 (2005) 24002.

[14] K. Nakao, S. Ito, K. Tomishige and K. Kunimori, Catal. Today 111 (2006) 316.

[15] T. Matsushima, Surf. Sci. Rep. 52 (2003) 1.

[16] A. Eichler, Surf. Sci. 498 (2002) 314.

[17] J. Lauterbach, G. Haas, H.H. Rotermund and G. Ertl, Surf. Sci. 294 (1993) 116. 


\section{Figure Captions}

Figure 1. (a) The formation rate of $\mathrm{CO}_{2}$ during $\mathrm{CO}$ oxidation on $\mathrm{Pd}(111), \operatorname{Pt}(111)$, and $\mathrm{Rh}(111)$, and (b) the Arrhenius plot obtained from Fig. 1(a). The total flux of reactants of $\left(\mathrm{CO}+\mathrm{O}_{2}\right)$ was 8.2 $\times 10^{18} \mathrm{~cm}^{-2} \mathrm{~s}^{-1}$ at the $\mathrm{CO} / \mathrm{O}_{2}=1$. The values of $\mathrm{Pd}(111)$ and $\mathrm{Pt}(111)$ are taken from Ref. [12,13]

Figure 2. IR emission spectra of $\mathrm{CO}_{2}$ desorbed by $\mathrm{CO}$ oxidation on $\mathrm{Rh}(111)$. The surface temperature $\left(T_{\mathrm{S}}\right)$ was $575-800 \mathrm{~K}$. The flux conditions are as descried in Figure 1. The emission intensity was normalized per unit of $\mathrm{CO}_{2}$ yield.

Figure 3. Surface temperature dependence of average vibrational temperature $\left(T_{\mathrm{V}}{ }^{\mathrm{AV}}\right)$ of $\mathrm{CO}_{2}$ formed in $\mathrm{CO}$ oxidation on $\mathrm{Pd}(111), \mathrm{Pt}(111)$ and $\mathrm{Rh}(111)$. The flux conditions are as described in Figure 1. The values of $\operatorname{Pd}(111)$ and $\operatorname{Pt}(111)$ are taken from Ref. [12,13].

Figure 4. Potential energy diagram for the $\mathrm{CO}$ oxidation on noble metal surfaces $(\mathrm{Pd}, \mathrm{Pt}, \mathrm{Rh})$. The $E_{\text {ini }}$ and $E_{\mathrm{TS}}$ are the potential energies in the initial and transition states, respectively. The $E_{\mathrm{a}}$ and $E_{\text {excited }}$ are the activation energy in $\mathrm{CO}$ oxidation and the excited energy of the product $\mathrm{CO}_{2}$, respectively (see Table 1).

Figure 5. Surface temperature dependence of (a) bending vibrational temperature $\left(T_{\mathrm{V}}{ }^{\mathrm{B}}\right)$ and (b) antisymmetric vibrational temperature $\left(T_{\mathrm{V}}{ }^{\mathrm{AS}}\right)$ of $\mathrm{CO}_{2}$ formed in $\mathrm{CO}$ oxidation on $\operatorname{Pd}(111)(\boldsymbol{\square}, \square)$, $\operatorname{Pt}(111)(\boldsymbol{\Delta}, \triangle)$ and $\operatorname{Rh}(111)(\boldsymbol{O}, \bigcirc)$. The flux conditions are as described in Figure 1. The values of $\operatorname{Pd}(111)$ and $\operatorname{Pt}(111)$ are taken from Ref. [12,13]. 
Table 1 Potential energies in the initial $\left(E_{\text {ini }}\right)$ and the transition $\left(E_{\mathrm{TS}}\right)$ states, the activation energies $\left(E_{\mathrm{a}}\right)$ and $\mathrm{O}-\mathrm{C}-\mathrm{O}$ angle $\left(\angle_{\mathrm{OCO}}\right)$ at the transition states for the $\mathrm{CO}$ oxidation over $\mathrm{Pd}(111), \operatorname{Pt}(111)$ and $\mathrm{Rh}(111)$ surfaces taken from Ref. [16 ${ }^{\mathrm{a}}$.

\begin{tabular}{cccc}
\hline & $\operatorname{Pd}(111)$ & $\operatorname{Pt}(111)$ & $\operatorname{Rh}(111)$ \\
\hline$E_{\text {ini }} \mathrm{b} / \mathrm{eV}$ & -2.38 & -2.12 & -2.91 \\
$E_{\mathrm{TS}} / \mathrm{eV}$ & -0.98 & -1.38 & -1.88 \\
$E_{\mathrm{a}}{ }^{\mathrm{c}} / \mathrm{eV}$ & 1.40 & 0.74 & 1.03 \\
$\angle \mathrm{OCO}$ & $112^{\circ}$ & & $112^{\circ}$ \\
\hline
\end{tabular}

${ }^{\text {a }}$ The zero of potential energies based on the free molecules $\left(\mathrm{CO}+1 / 2 \mathrm{O}_{2}\right)$.

${ }^{\mathrm{b}}$ The initial states means the states of $\mathrm{CO}$ and $\mathrm{O}$ adsorbed on surfaces.

${ }^{\mathrm{c}} E_{\mathrm{a}}=E_{\mathrm{TS}}-E_{\mathrm{ini}}$ 

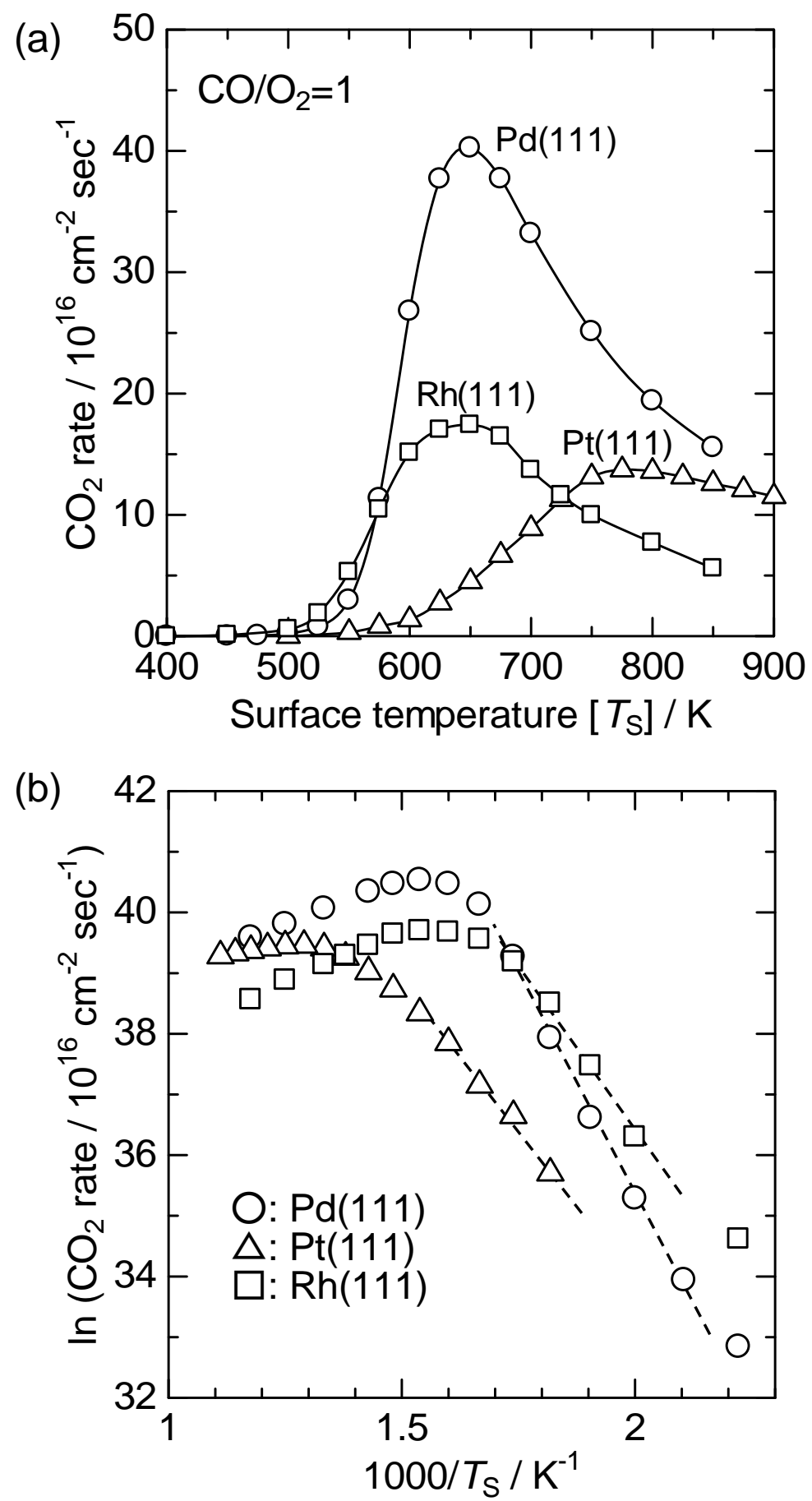

Figure 1. (a) The formation rate of $\mathrm{CO}_{2}$ during $\mathrm{CO}$ oxidation on $\mathrm{Pd}(111), \operatorname{Pt}(111)$, and $\mathrm{Rh}(111)$, and (b) the Arrhenius plot obtained from Fig. 1(a). The total flux of reactants of $\left(\mathrm{CO}+\mathrm{O}_{2}\right)$ was $8.2 \times$ $10^{18} \mathrm{~cm}^{-2} \mathrm{~s}^{-1}$ at the $\mathrm{CO} / \mathrm{O}_{2}=1$. The values of $\operatorname{Pd}(111)$ and $\operatorname{Pt}(111)$ are taken from Ref. $[12,13]$. 


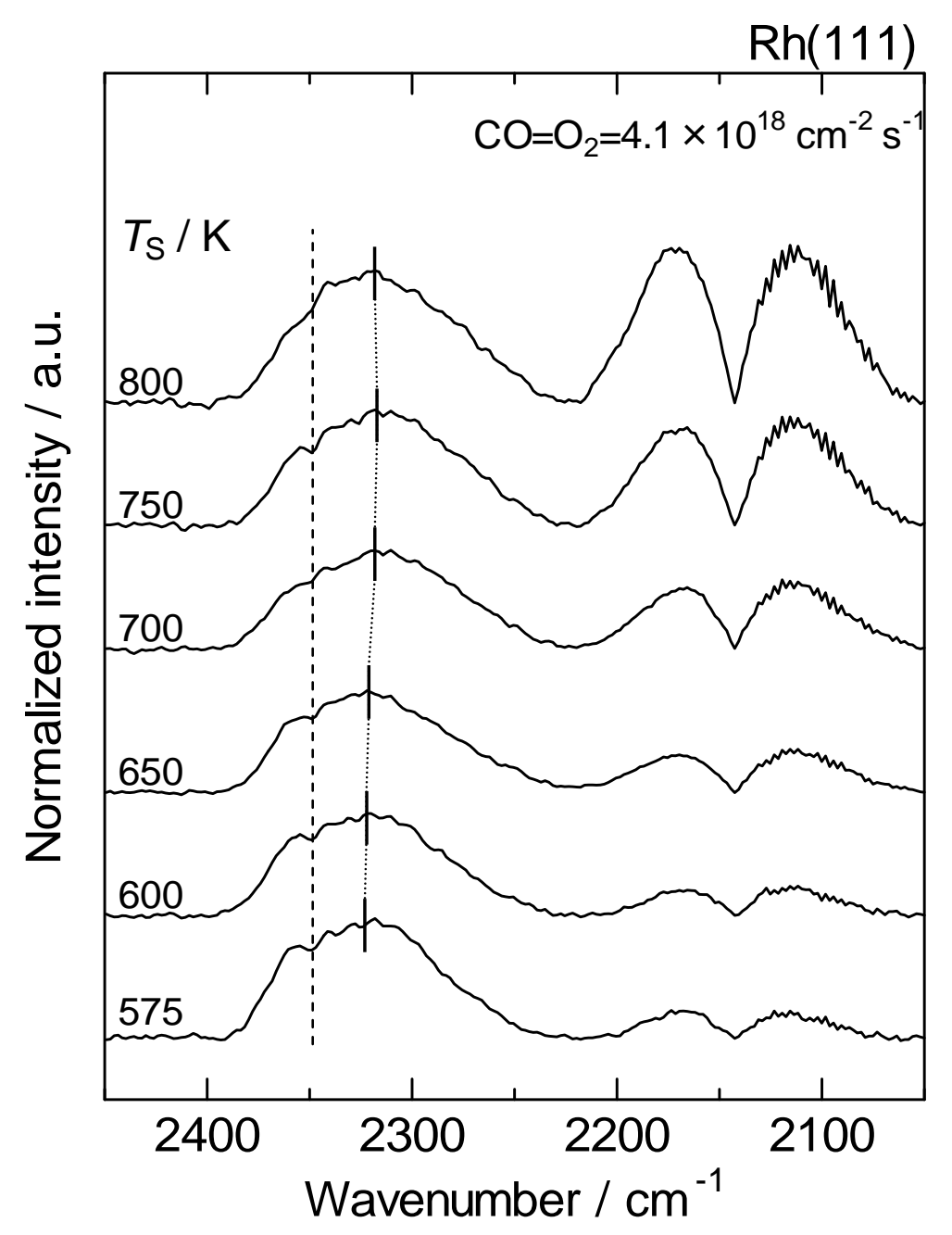

Figure 2. IR emission spectra of $\mathrm{CO}_{2}$ desorbed by $\mathrm{CO}$ oxidation on $\mathrm{Rh}(111)$. The surface temperature $\left(T_{\mathrm{S}}\right)$ was $575-800 \mathrm{~K}$. The flux conditions are as described in Figure 1 . The emission intensity was normalized per unit of $\mathrm{CO}_{2}$ yield. 


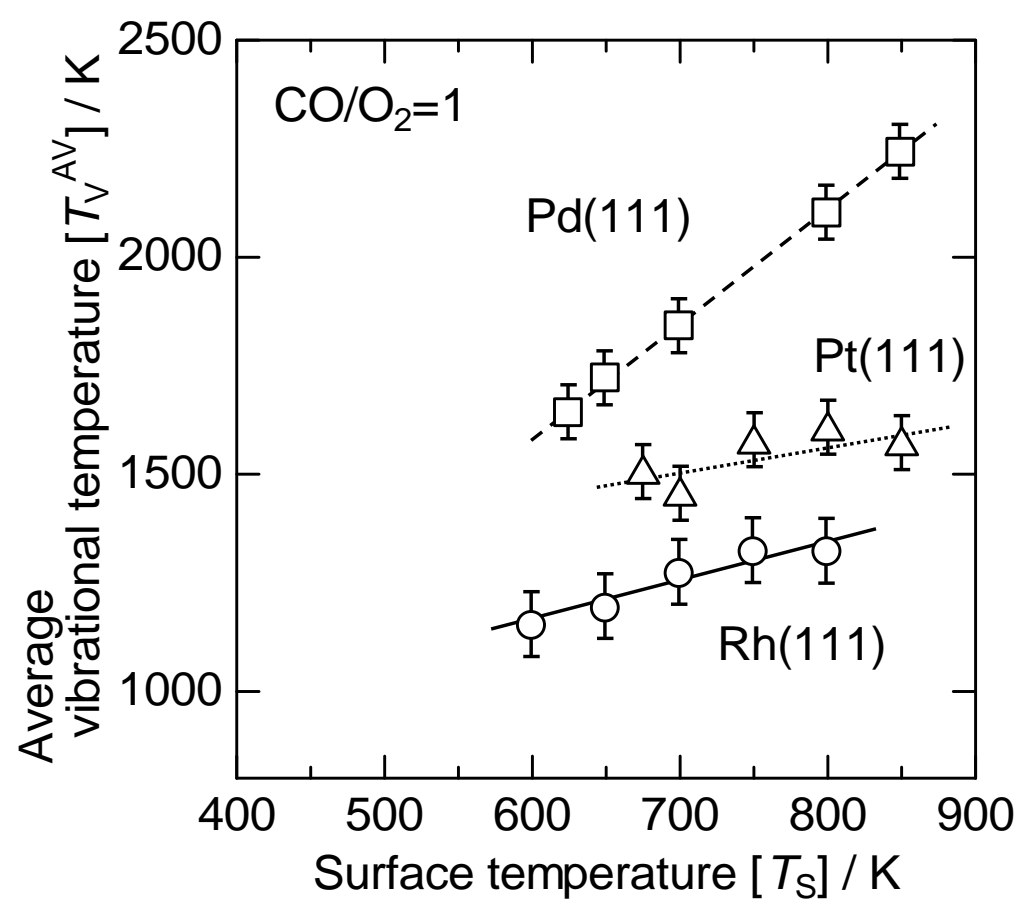

Figure 3. Surface temperature dependence of average vibrational temperature $\left(T_{\mathrm{V}}^{\mathrm{AV}}\right)$ of $\mathrm{CO}_{2}$ formed in $\mathrm{CO}$ oxidation on $\mathrm{Pd}(111), \mathrm{Pt}(111)$ and $\mathrm{Rh}(111)$. The flux conditions are as described in Figure 1. The values of Pd(111) and $\operatorname{Pt}(111)$ are taken from Ref. [12,13]. 
Figure 4. Potential energy diagram for the $\mathrm{CO}$ oxidation on noble metal surfaces $(\mathrm{Pd}, \mathrm{Pt}, \mathrm{Rh})$. The $E_{\mathrm{ini}}$ and $E_{\mathrm{TS}}$ are the potential energies in the initial and transition states, respectively. The $E_{\mathrm{a}}$ and $E_{\text {excited }}$ are the activation energy in $\mathrm{CO}$ oxidation and the excited energy of the product $\mathrm{CO}_{2}$, respectively (see Table 1). 
(a)

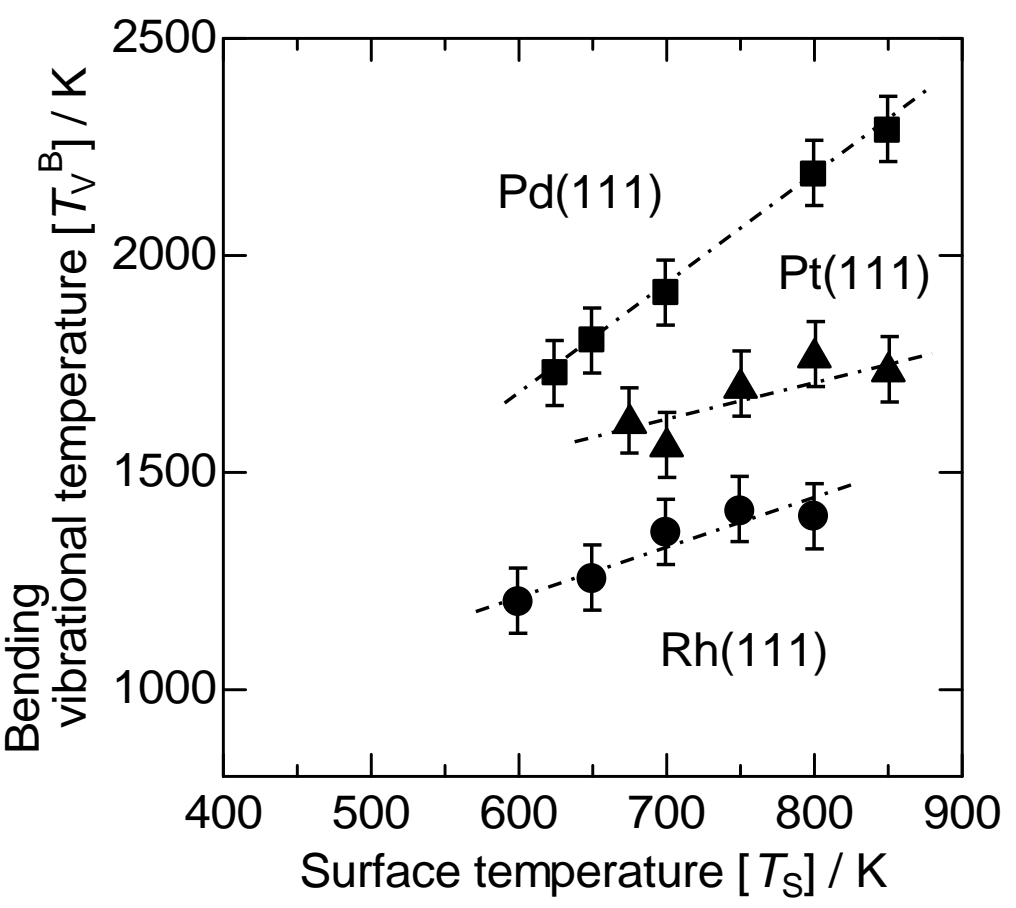

(b)

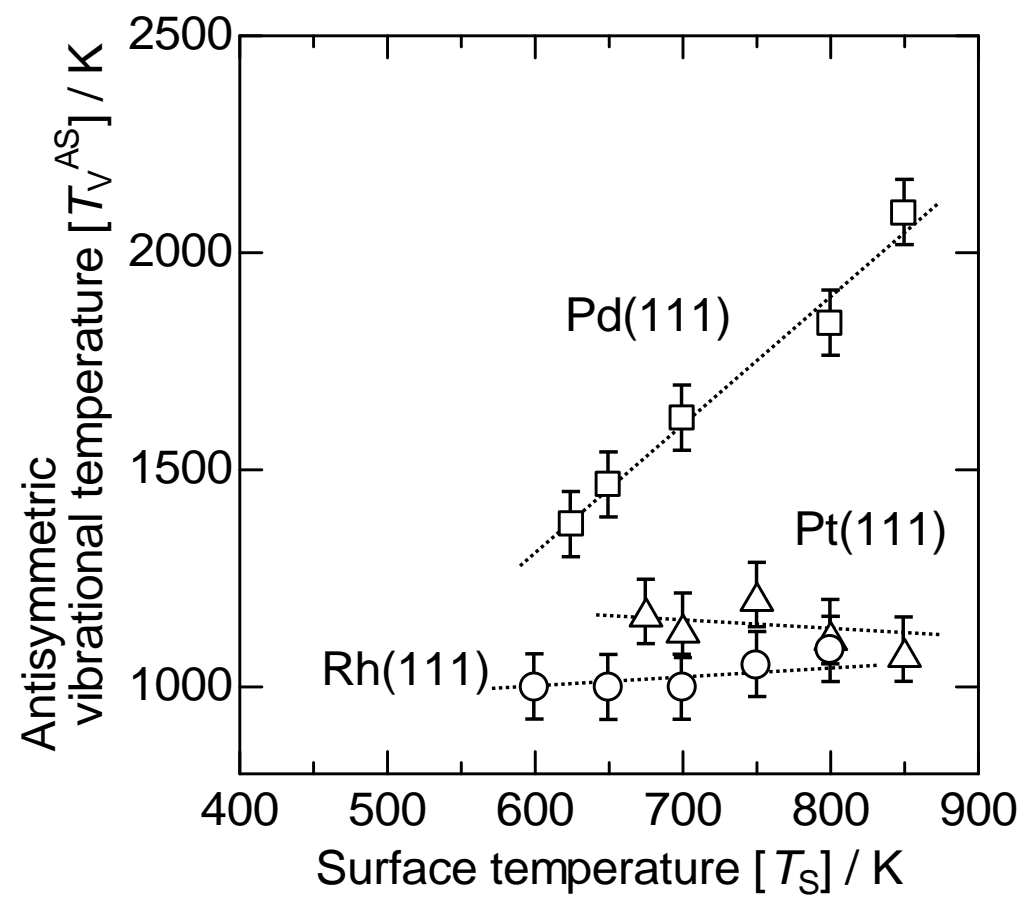

Figure 5. Surface temperature dependence of (a) bending vibrational temperature $\left(T_{\mathrm{V}}^{\mathrm{B}}\right)$ and (b) antisymmetric vibrational temperature $\left(T_{\mathrm{V}}{ }^{\mathrm{AS}}\right)$ of $\mathrm{CO}_{2}$ formed in $\mathrm{CO}$ oxidation on $\operatorname{Pd}(111)(\mathbf{\square}, \square)$, $\operatorname{Pt}(111)(\boldsymbol{\Delta}, \triangle)$ and $\operatorname{Rh}(111)(\bullet, \bigcirc)$. The flux conditions are as described in Figure 1. The values of $\operatorname{Pd}(111)$ and $\operatorname{Pt}(111)$ are taken from Ref. [12,13]. 